\title{
INTRODUCTION TO ANALYZING INTERNAL GROWTH STRUCTURES: Identification of the Negative d Plane in Natural Ruby
}

\author{
By Christopher P. Smith
}

Growth-structure analysis has become increasingly important as a gemological tool for locality classification and distinguishing between natural and synthetic gemstones. This article presents the methods and instruments needed to analyze the internal growth structures of corundum. As an application of this testing procedure, the negative rhombohedral $\mathrm{d}(0112)$ plane is documented as part of the crystal habit in a small number of natural rubies-both as a subordinate form and, for the first time in natural rubies, as a dominant crystal form. Until recently, this crystal face was primarily associated with flux-grown synthetic rubies and sapphires.

\section{ABOUT THE AUTHOR}

Mr. Smith is manager of Laboratory Services, Gübelin Gemmological Laboratory, Maihofstrasse 102, 6000 Luceme 9, Switzerland.

Acknowledgments: The author thanks D. E. J. Gubelin, $S$. Repetto, and various clients of the Gübelin Gemmological Laboratory for loaning samples; Dr. A. Peretti for introducing him to this testing procedure; and Dr. K. Schmetzer for his continuing work on the application of intemal growth-structure analysis in gem identification, as well as his thoughtful review of earlier drafts. U. Gottscheu manufactured the stone holder modification, and the staff of the Gübelin Gemmological Laboratory provided useful comments. Readers interested in more information on the instrumentation and techniques presented here should contact the author. All photos are by the author unless otherwise indicated. All growth-structure photomicrographs are in transmitted light.

Gems \& Gemology, Vol. 32, No. 3, pp. 170-184. C. 1996 Gemological Institute of America

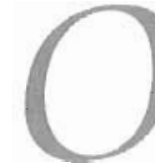

ver the past several years, the analysis of crystal habits and internal growth features observed in gemstones has gone beyond the realm of purely academic crystallography to applications in gem identification. The wealth of information leamed through the determination of external habits and internal growth structures, which reflect the conditions in which the gem grew, can aid in (1) the separation of natural and synthetic gem materials, as well as (2) the identification and characterization of gemstones from different deposits around the world (figure 1).

For example, the type of twinning is an important factor in separating natural from synthetic amethyst (see, e.g., Crowningshield et al., 1986; Koivula and Fritsch, 1989; Kiefert and Schmetzer, 1991c). In diamond, internal growth structures (commonly referred to as graining) can affect the clarity of the stone (see, e.g., Kane, 1980) and be responsible for certain color manifestations (see, e.g., Kane, 1980; Hofer, 1985; Kane, 1987). These and other growth structures also aid in the separation of natural and synthetic diamonds (see, e.g., Shigley et al., 1992, 1993; Sunagawa, 1992; Rooney et al., 1993; and the Welbourn et al., 1996, article elsewhere in this issue on the new De Beers DiamondView instrument). Beryl classification from various sources, in addition to the separation of natural from synthetic emeralds, has also benefited from the study of internal and external growth features (see, e.g., Lind et al., 1986; Kiefert and Schmetzer, 1991b; Schmetzer et al., 1991).

In corundum in particular, growth-structure analysis has become a standard procedure in many laboratories for both source determination and natural versus synthetic distinctions (see, e.g., Schmetzer, 1986a and b; Schmetzer, 1987; Kiefert, 1987; Kiefert and Schmetzer, 1987, 1988, 1991c; Hänni and Schmetzer, 1991; Peretti and Smith, 1993; Hänni 

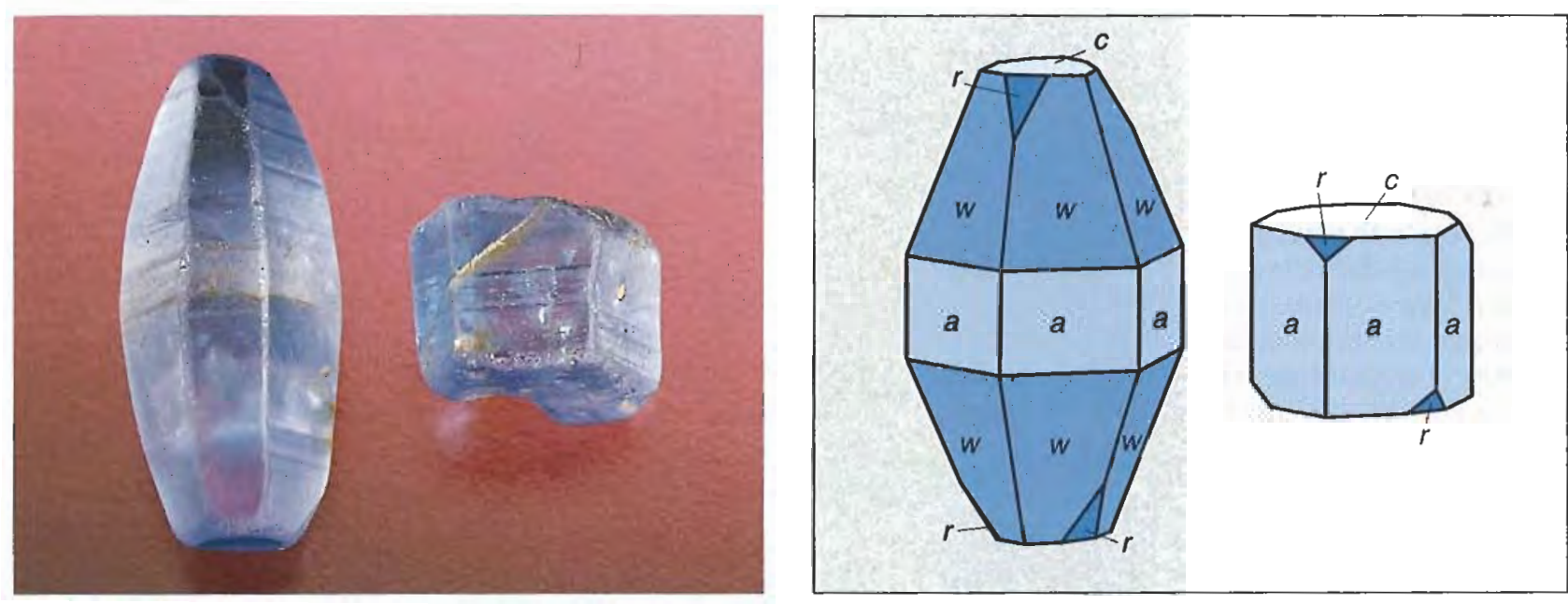

Figure 2. The external form, or habit, of a crystal is made up of a collection of various crystal faces. The number and relative prominence of these crystal faces can have a significant influence on the overall shape of the crystal. Shown here are bipyramidal (left) and tabular (right) blue sapphire crystals from Sri Lanka. The line diagrams illustrate which crystal faces comprise the habits of these two crystals: the basal pinacoid c (0001), the positive rhombohedron $\mathrm{r}(1011)$, the hexagonal dipyramid w (1121), and the second-order prism a (1120). Photo by Shane F. McClure.

growth planes were at one point extemal crystal faces. For consistency, the word plane will be used to refer to internal crystal forms, and the word faces will be reserved for describing external crystal forms.) Minerals form over a long period of time-sometimes continuously and sometimes discontinuously-until the conditions of the formation environment can no longer sustain that mineral's growth. This change in conditions can happen for a variety of reasons. For example, the crystal may be removed from the growth environment by geologic forces, or the growth environment no longer has the chemical/physical requirements (composition of fluids, temperature, pressurel to support the continued formation of that mineral, or there may be no more space for expansion because of competition from other minerals.

The intemal structures that indicate the growth of a crystal can be compared to the "rings" of a tree. Just as each "ring" represents one year's growth of tree bark, the internal growth structures illustrate various stages in the history of a crystal's formation. Intemal growth features can be observed in transparent gem materials in a variety of ways: as color zoning (which can fluctuate between the different stages of growth); by inclusions that form and concentrate along crystal faces, or coat the crystal's entire surface at one growth stage and then are enclosed by later phases / the latter is how "phantoms" are formed); or by the presence of "lines" that represent the interface or contact plane between consecutive stages of growth. These lines generally are visible with a microscope only when the interior of the gemstone is viewed in a direction parallel, or nearly parallel, to the traces of a specific plane, particularly if the stone is immersed in a liquid of similar refractive index (to reduce the reflection of light).

The appearance of these lines can be visualized by imagining a common type of window in which two sheets of glass have been vacuum sealed together. When you look perpendicular to the glass plane (i.e., as you would normally look through a window), the objects on the other side are not obstructed. However, if you examine the glass parallel to its main surface (i.e., along the edge), a "line" is visible where the two sheets of glass meet.

In 1985, Dr. Karl Schmetzer published his first paper dealing with the methods for determining internal growth structures in some uniaxial gemstones, with specific focus on corundum, beryl, and quartz (see also Schmetzer, 1986a). For a more indepth discussion on methods and applications of determining growth structures in some uniaxial gemstones, the reader is referred to these papers and others by Schmetzer $(1985,1986 \mathrm{a}$ and b), Kiefert and Schmetzer (1991a-c), and Peretti et al. (1995). Following is a brief, step-by-step description of how to use this technique; it has been written specifically for those gemologists, like the author, who do not have a formal background in crystallography.

The Technique. The manner in which specific crystal planes can be identified relates to: (1) the position, or the angle, that the planes form relative to the optic-axis direction of the uniaxial gemstone; and (2) the angle created by the joining of two planes. In the technique used by the author to iden- 
tify crystal planes, the equipment includes: a stone holder, modified by the author, which allows for rotation about both the vertical and horizontal axes (Box A); a horizontal microscope; an immersion cell containing methylene iodide; , and a light source located behind the gemstone so light is transmitted through it (figure 4). Note that growth structures, color zoning, and the like, can also be seen, but not measured, with a standard binocular microscope using darkfield and various other illumination techniques. However, immersing the gemstone in a liquid will reduce the distortion of light and other detrimental effects, thereby significantly improving the visibility (and measurability) of the growth structures. The recommended procedure is as follows:

First examine each specimen with magnification in the immersion liquid to locate any color banding or other structural features that might be present. Then position the stone in the stone holder so that the direction of the growth planes selected for identification is oriented vertically, that is, perpendicular to the platform base that holds the immersion cell, thus allowing for the most accurate measurement of the angle between the optic-axis direction and the growth plane to be identified. The author has added this first step to the methods described by Schmetzer $(1985,1986 \mathrm{a}$ and b) and Kiefert and Schmetzer (1991a-c), in order to guarantee the most accurate measurement for those just beginning to use this testing method. When the growth planes are not in a vertical direction, but rather are at an angle, the angles measured may be off by a couple of degrees, thereby decreasing the accuracy of the technique.

Next, center the optic axis (c-axis) of the gemstone both horizontally and vertically, parallel to the observer's field of view. This is accomplished by using a pair of crossed polarizing filters and the dual-axis stone holder, which allows for a pivotal tilting both forward and backward, as well as a $360^{\circ}$ rotation. By pivoting and rotating the stone holder (and the gemstone), look for the interference rings to converge toward the center of the stone (figure 5). At a certain point, you will notice the interference rings shift from converging to diverging. This indicates that the optic axis of the stone has just been "passed over." Here, make smaller adjustments to center the stone in that small area between where the interference rings converge and diverge.

During the final centering of the optic axis, very subtle movements left to right and backward to forward will cause the gemstone to go from white to dark to white again (whereas more exaggerated movements will again display the interference rings). When the optic axis is centered, the gemstone should appear essentially black. It may take some practice to become familiar with this procedure. Nevertheless, the accurate centering of the optic axis is essential to the correct identification of the growth planes to be measured.

Figure 3. Internal growth structures reveal the history of a gem's formation. Each internal growth plane seen in a stone was once a face on the original crystal as it grew. Changes in the formation environment can change the presence and prominence of the various faces, providing clues to the origin of the stone. Often one can see the succession of crystal habits that formed over time. In this idealized example of a ruby from Mong Hsu (Myanmar), the optic axis is located parallel to the length of the stone, and the small, horizontal, basal growth planes are positioned down the middle. An equal amount of growth-structure information is present to the left and right, revealing a habit of $\mathrm{c}, \mathrm{n}$, and $\omega$. Note that most gemstones do not reveal such a well-centered sequence of growth structures; typically, one side is either less complete than the other or absent. Immersion, magnified $10 \times$.

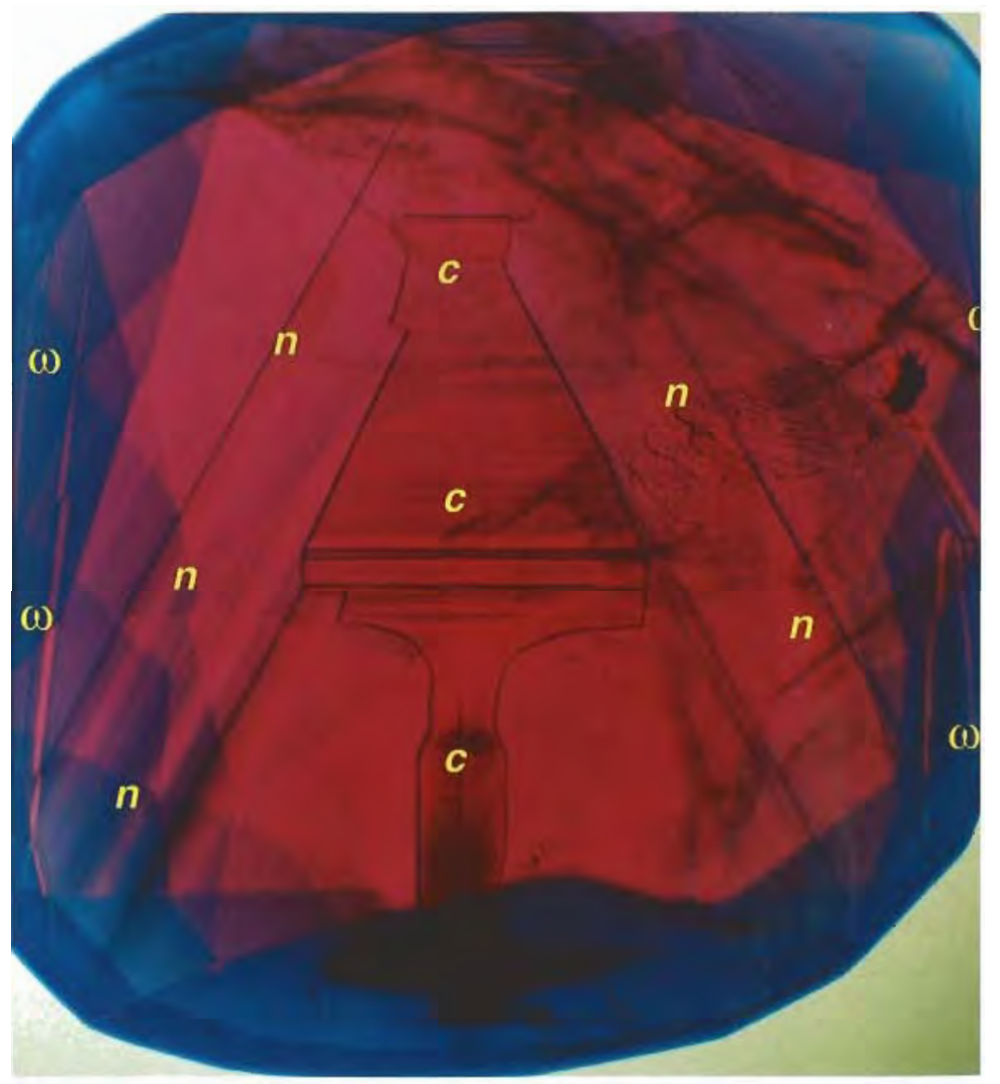




\section{BOX A: The Modified Stone Holder ANd Its Benefits}

Under optimal measuring conditions, the "optic axis" method has an accuracy of approximately $\pm 1^{\circ}$ (Schmetzer, 1985, 1986a; Kiefert and Schmetzer, 1991a). These optimal conditions are present when the stone holder can be maintained in an essentially vertical position, so that the centered optic axis remains parallel to the observer's field of view /along a horizontal rotation planel, even after a $180^{\circ}$ turn of the stone and stone holder. However, because the axial orientation of a faceted gemstone is usually random, the observer commonly must tilt the stone holder either forward or backward to center the optic axis. It has

Figure A-1. (a) When the stone holder and gemstone are tilted to large degrees, the optic axis is no longer parallel to the observer's field of view, thereby increasing the potential error factor in the measurement of the angles and making it more difficult to separate the different crystal planes. (b) With the modified stone holder, major corrections can be made by rotating the gemstone itself, so that the stone holder remains vertical and the optic axis stays parallel to the observer's field of view, even after a $180^{\circ}$ turn. This permits optimal measuring conditions and accuracy. The arrow shows the optic-axis direction.
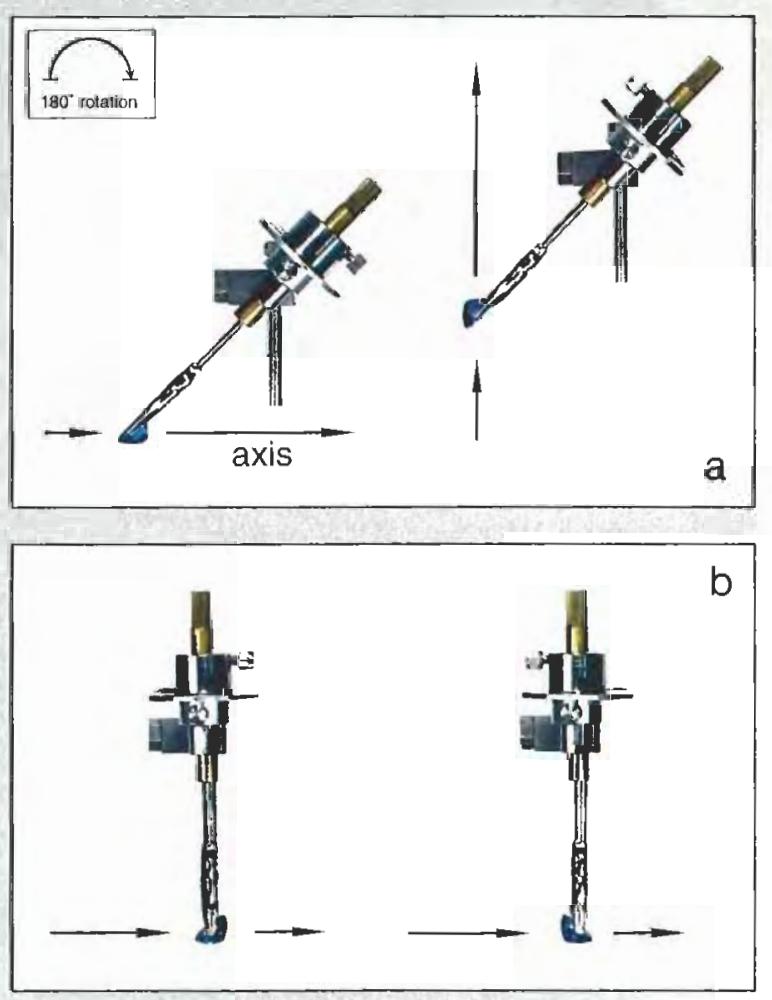

been proposed that the observer can tilt the stone holder up to approximately $40^{\circ}$ and still get accurate readings (Kiefert and Schmetzer, 1991a). In the author's experience, however, centering the optic axis frequently requires that the stone holder be tilted to this degree or even further. Yet, on a $180^{\circ}$ rotation or even a portion thereof, the optic-axis direction does not remain parallel along the horizontal rotation plane (figure A1a). This increases the error factor and makes the determination of individual crystal planes more difficult.

The author's modification to the basic stone holder consists of two independently rotating, slightly curved, grooved channels (figure A-2). These channels allow for an additional rotation axis about the vertical plane. Therefore, the observer does not have to tilt the stone holder to large degrees, or reposition the gemstone in the stone holder, to center the optic axis of certain gemstones. Instead, he or she can rotate the gemstone itself by means of the channels, so that the c-axis maintains a parallel rotation about the horizontal plane and the field of view (figure A-1b). With this new rotation capability, the operator can correct major deviations, leaving the "fine tuning" adjustments to the tilting movement. It should not be necessary for the tilting movement to deviate more than approximately $5^{\circ}$ either forward or backward from the vertical position, thereby always maintaining optimal measurement conditions. In addition, after locating the optic axis, the operator can now turn the gemstone $90^{\circ}$ along the vertical rotation axis, to view the growth structures perpendicular to the c-axis lagain refer to figure 3 ) without removing the gemstone and repositioning it in the stone holder.

Figure A-2. The author's modification to the basic stone holder consists of two independently rotating grooved channels, which allow for an additional rotation capability so that the $c$-axis remains in a vertical position. Photo by Shane F. McClure.

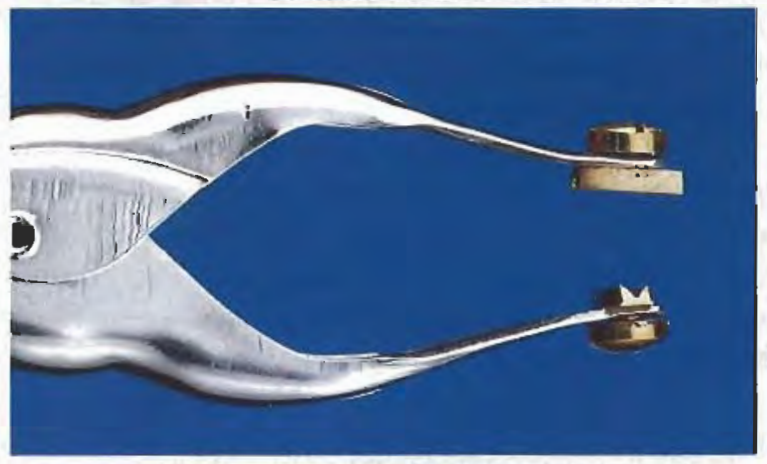


A simple method to check whether the optic axis is centered involves holding a jeweler's loupe between the microscope and the immersion cell. If the gemstone is centered properly, the loupe will act as a coniscope lens / similar to the glass sphere used with a polariscopel, revealing the uniaxial optic figure.

Once the optic axis is centered, remove the polarizing filters and use the set screw to position the pointer of the stone holder at the $0^{\circ}$ mark on the indicator dial (figure 6). Then rotate the stone and stone holder (left or right) until a vertical series of growth features is sharply delineated, often by color zoning (figure 7); the position of the pointer on the dial will show how many degrees these growth features are located from the optic-axis direction (figure 8). This number defines which crystal plane is represented by the growth features being examined (see table 1 for the crystal planes seen in conundum and their corresponding angles from the c-axis|. The prism planes $a(11 \overline{2} 0)$ are seen at $0^{\circ}$ (because they are parallel to the optic axis); whereas the basal pinacoid c (0001), which is perpendicular to the optic axis, has the largest potential reading, $90^{\circ}$ (again, see table 1 ). All other crystal planes are located at angles between these two. Typically, a gemstone contains more than one series of growth planes. When complex growth structures are encountered, it may be helpful to center the optic axis first, and then rotate the stone holder as previously described to identify which growth planes are present.

Connecting growth planes can also be identified using a specially designed eyepiece that attaches to one of the microscope oculars. This eyepiece acts as a mini-goniometer, an instrument used by crystallographers to measure angles between crystal faces, enabling measurement of the angles created by connecting crystal planes within a stone (see, e.g., Kiefert and Schmetzer, 1991a). Contained within the eyepiece are two independently rotating disks, one with two lines intersecting at $90^{\circ}$ (creating a cross) and the other consisting of small numbered marks around the periphery, indicating $360^{\circ}$ in a complete circle. By lining up the longer "cross hair" parallel to one series of crystal planes and then rotating it so that it is parallel to the other series of crystal planes, one can use the scale around the periphery to determine the number of degrees in the angle created by the meeting of two or more crystal planes. (Author's note: The eyepiece described here is no longer commercially available from the Leica Corp. The reader is therefore referred to Kiefert and

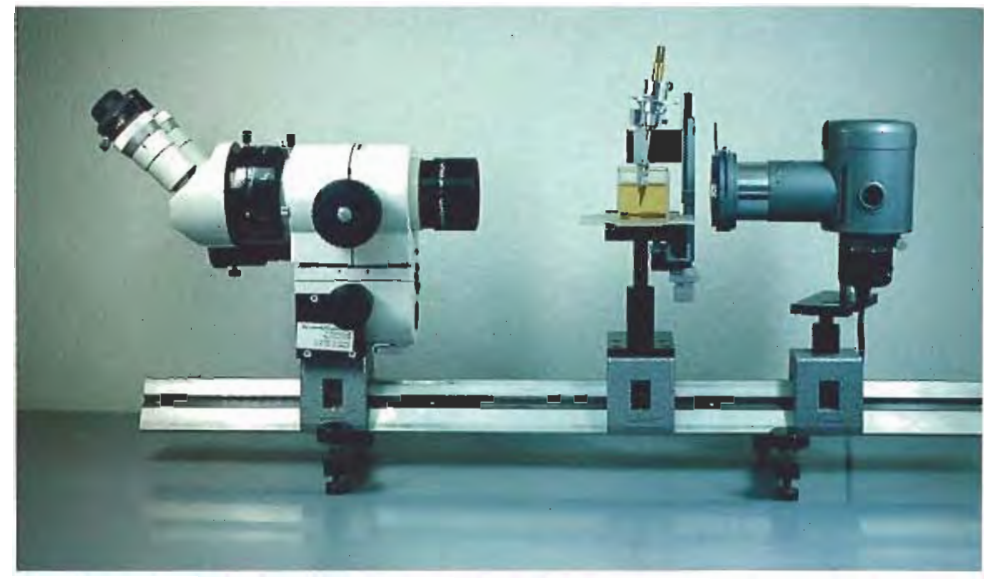

Figure 4. Internal growth structures are analyzed most readily with a horizontal microscope set-up such as this one, with the gemstone immersed in a container filled with methylene iodide and a light source positioned opposite the microscope head so as to transmit light through the sample. A horizontal microscope has the additional advantage of distanc ing the operator from the methylene iodide fumes.

Schmetzer, 1991a, for a description of commercially available microscope oculars with "cross hairs" and an additional scale to measure the angles, which is

Figure 5. Centering the optic axis of a miaxial gemstone requires rotating the stone holder left to right as well as tilting it forward and backward. The interference rings should converge toward the center of the gemstone as the optic axis becomes centered. At the point where the optic axis is centered, the stone should appear essentially black. Also note the faint vertical growth planes visible in this sample. Immersion, between crossed polarizers, magnified $10 \times$.

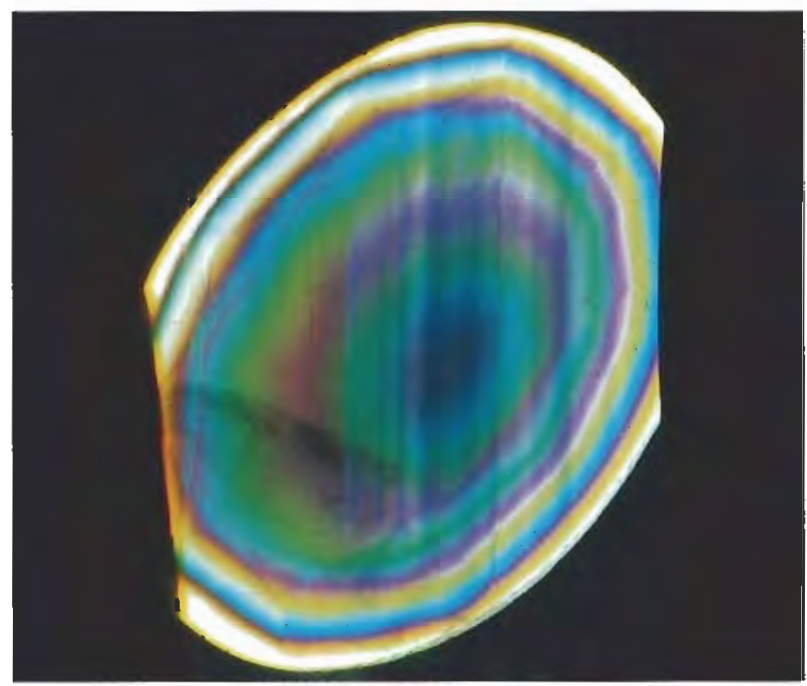




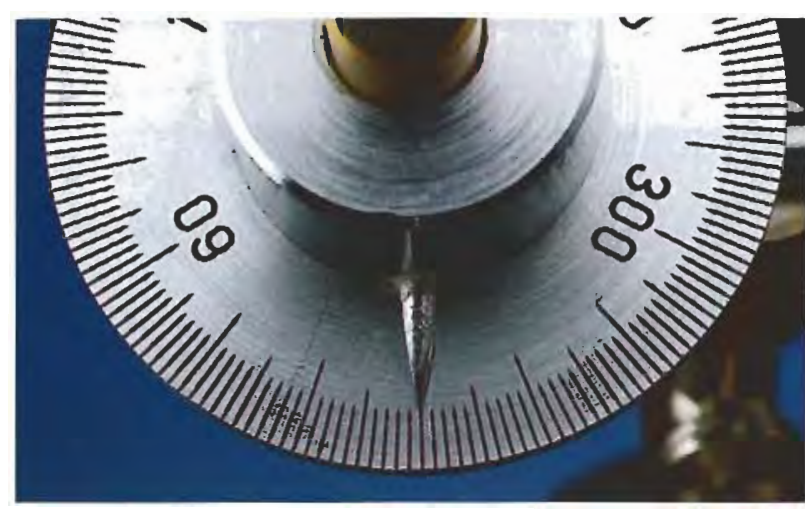

Figure 6. Once the optic axis has been successfully centered, before the stone is rotated to observe the growth features, the pointer must be positioned at the $0^{\circ}$ mark on the indicator dial. Photo by Shane F. McClure.

added to the exterior of the eyepiece tube of the microscope.)

In contrast to the first ("optic axis") method, this second ("connecting planes") procedure does not depend on finding the optic-axis direction of the gemstone. (However, it is recommended that less

Figure 7. One of the most obvious ways to identify sharpened growth structures is through color zones, or bands, the thickness of which may fluctuate between consecutive periods of crystal growth. Shown here are broad blue color bands alternating with narrow colorless bands, parallel to dipyramidal v ( $44 \overline{8} 3$ ) planes, in a sapphire from Kashmir. The vertical growth planes are at $15.4^{\circ}$ from the optic axis direction, and the angle created at the junction of the $\mathrm{v}-\mathrm{v}$ planes is $123^{\circ}$. Immersion, magnified 15x.

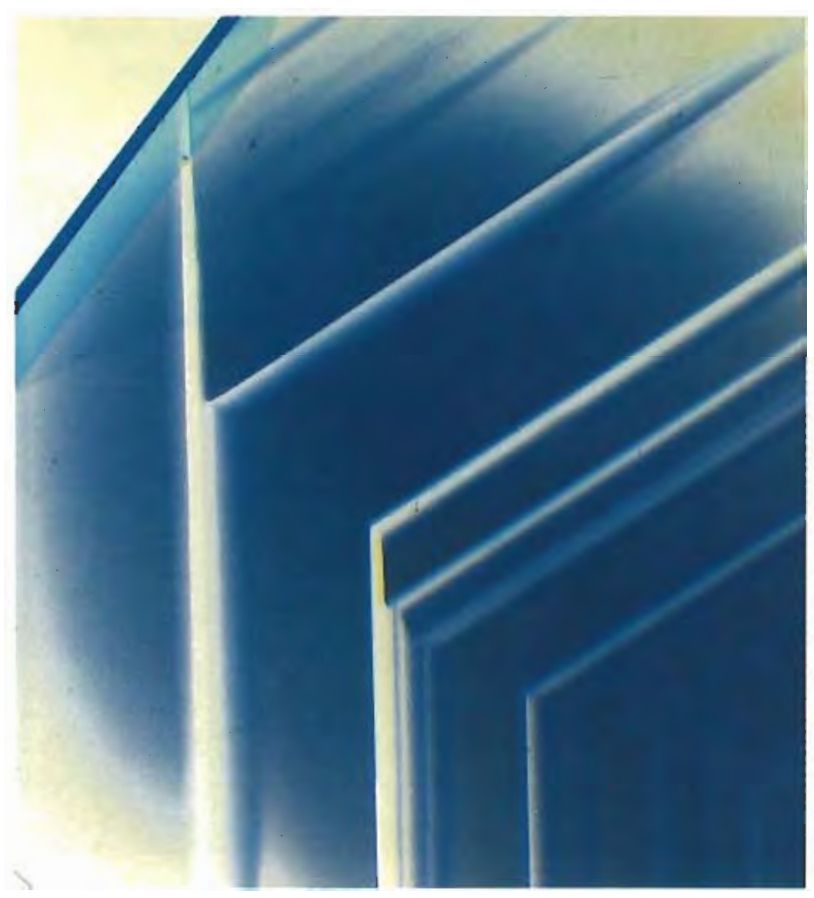

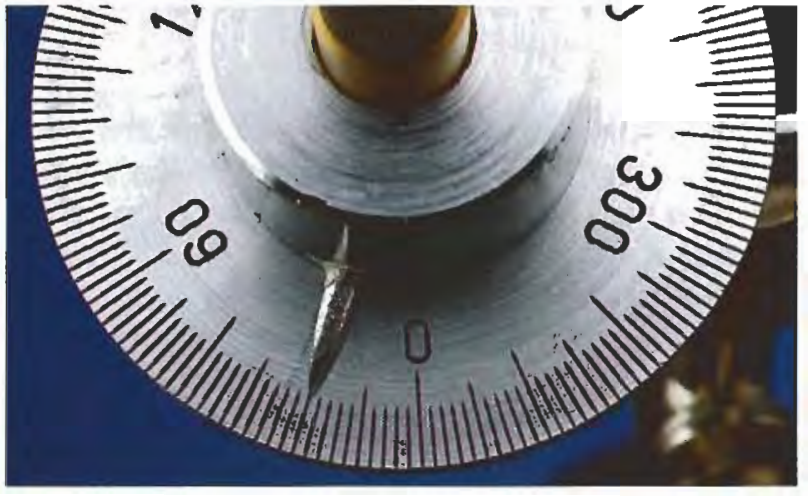

Figure 8. By rotating the stone holder until the growth features are sharply defined, the pointer will show the number of degrees, on the indicator dial, that the growth features are located from the optic-axis direction of the gemstone. The measurement of 20 shown here identifies a series of dipyramidal w (112̄1) planes, which are located characteristically at $20.1^{\circ}$ from the optic-axis direction, Photo by Shane F. McClure.

experienced practitioners locate and identify at least one series of growth planes initially by the optic-axis method.) What is critical to the accurate measurement of the angles is that both series of growth planes and the points at which they meet are very sharp. With our knowledge of the exact angles formed by various connecting crystal planes /see table 2 for the "interfacial" crystal angles for corundum), once one set of crystal planes has been identified, connecting crystal planes can be identified without requiring reorientation of the stone to the

TABLE 1. The primary crystal planes and angles encountered in natural and synthetic corundum. ${ }^{a}$

\begin{tabular}{|c|c|c|c|}
\hline Cryslal plane & Designation & $\begin{array}{c}\text { hk| } \\
\text { indices }\end{array}$ & $\begin{array}{c}\delta \\
\text { (angle from the } \\
c \text {-axis) }\end{array}$ \\
\hline $\begin{array}{l}\text { Second-order } \\
\text { hexagonal prism }\end{array}$ & $a^{b}$ & $(11 \overline{20})$ & $0^{\circ}$ \\
\hline $\begin{array}{l}\text { Second-order } \\
\text { hexagonal } \\
\text { dipyramids }\end{array}$ & $\begin{array}{l}\omega^{b} \\
v^{b} \\
Z^{b} \\
v^{b} \\
w^{b} \\
n\end{array}$ & $\begin{array}{c}(1414 \overline{28} 3) \\
(44 \overline{8} 1) \\
(22 \overline{4} 1) \\
(44 \overline{8} 3) \\
(11 \overline{2} 1) \\
(22 \overline{4})\end{array}$ & $\begin{array}{r}4.5^{\circ} \\
5.2^{\circ} \\
10.4^{\circ} \\
15.4^{\circ} \\
20.1^{\circ} \\
28.8^{\circ}\end{array}$ \\
\hline $\begin{array}{l}\text { Positive } \\
\text { rhombohedron }\end{array}$ & $r$ & (10于1) & $32.4^{\circ}$ \\
\hline $\begin{array}{l}\text { Negative } \\
\text { rhombohedron }\end{array}$ & $d$ & $(01 \overline{1} 2)$ & $51.8^{\circ}$ \\
\hline $\begin{array}{l}\text { Negative } \\
\text { rhombohedron }\end{array}$ & $\gamma^{c}$ & $(01 \overline{1} 5)$ & $72.5^{\circ}$ \\
\hline Basal pinacoid & $C$ & $(0001)$ & $90^{\circ}$ \\
\hline
\end{tabular}

${ }^{a} \alpha-\mathrm{At}_{2} \mathrm{O}_{3}$, trigonal cryslal class $\mathrm{O}_{39}=32 / \mathrm{m}$. Adapted from Kietert and Schmelzer, $1991 \mathrm{a}$ b More lypically seen in natural corundum.

${ }^{c}$ More typicaliy seen in synthetic corundum. 


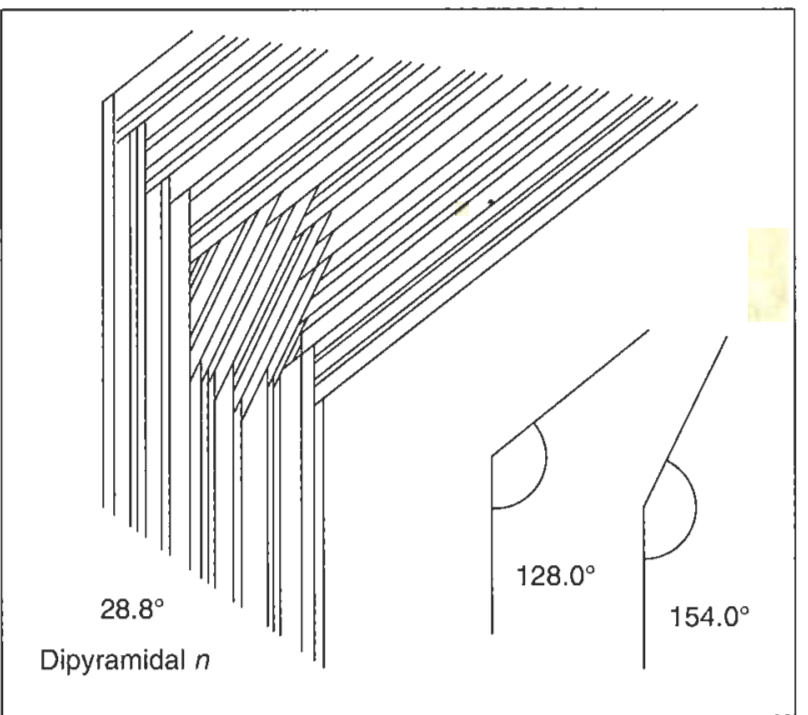

Figure 9. A second method of identifying internal growth structures uses a special eyepiece that is placed on one of the microscope oculars. It has a $360^{\circ}$ scale around the periphery, and cross-hairs with which to measure the angle from one growth plane to a connecting plane-that is, the angle formed by the intersection of the two planes. In this illustration, the vertical lines have been identified, by the first (optic-axis) method described, as dipyramidal $\mathrm{n}$ (22.43) planes, with a measurement of $28.8^{\circ}$ from the optic axis direction (see table 1). By determining the number of degrees between the n planes and the connecting planes, one can identify the remaining growth planes as positive rhombohedral $\mathrm{r}(10 \overline{1} 1)$ planes, with an angle of $154^{\circ}$, and $a$ second series of dipyramidal n planes, with an angle of $128^{\circ}$ (see table 2).

optic axis (figure 9). When used in combination, the two methods provide a cross-check system.

During growth-structure analysis, a helpful method to study the crystal forms is to examine the gemstone perpendicular to the c-axis, that is, parallel to the basal growth structures (again, see figure 3). This is also the best way to determine changes in "habit" that took place during the growth of the original crystal. For a more complete description of this procedure, the reader is referred to Peretti et al. (1995, pp. 8-9).

\section{THE NEGATIVE $d$ PLANE IN NATURAL RUBY}

Background. The study and determination of the crystal faces and habits for corundum is certainly not new to crystallography. For the most complete collection of corundum habits from various natural sources, the reader is referred to Victor Goldschmidt's Atlas der Krystallformen, published in 1918. Over the past decade, however, this analysis has taken the additional dimension of aiding in the separation of natural and synthetic corundums of various colors (Schmetzer, 1985, 1986a and b, 1987; Kiefert and Schmetzer, 1986, 1988, 1991c; Smith, 1992; Smith and Bosshart, 1993; Hänni et al., 1994; Schmetzer ct al., 1994). Because consistent and reproducible crystal synthesis requires a controlled growth environment, most synthetic corundums display crystal habits that are typical of the specific methods (and uniform conditions) by which they are manufactured. In contrast, as a result of inconsistencies and fluctuations in the geologic conditions present during their formation, natural corundums display a much wider variety of crystal habits.

The structural differences between natural and synthetic corundums may be seen in a variety of attributes, including the presence or prominence of certain crystal planes, color-zoning characteristics, habit variations, combinations of crystal planes, and systems of twin lamellae. Of the crystal planes observed in flux-grown synthetic corundums produced by the various manufacturers /such as Chatham, Douros, Kashan, Knischka, and Ramaura), the negative rhombohedral $d(01 \overline{1} 2)$ plane was found to be present with a frequency and prominence that has not been observed in natural corundums (Schmetzer, 1985, 1986a and b; Kiefert and Schmetzer, 1991a-c; Hänni et al., 1994). The negative $d$ plane is positioned at $51.8^{\circ}$ (again, see table 1) from the optic-axis direction. The negative $d$ face is located at the terminations (or ends) of a

TABLE 2. The angles formed by the meeting of two crystal planes in natural and synthetic corundum.

\begin{tabular}{lrrrrr}
\hline $\begin{array}{l}\text { Crystal } \\
\text { planes }\end{array}$ & Angle & $\begin{array}{c}\text { Crystal } \\
\text { planes }\end{array}$ & $\begin{array}{c}\text { Angle } \\
\left(90+\delta^{a}\right)\end{array}$ & $\begin{array}{c}\text { Crystal } \\
\text { planes }\end{array}$ & $\begin{array}{c}\text { Angle } \\
\left(180-\delta^{a}\right)\end{array}$ \\
\hline$a-a$ & $120.0^{\circ}$ & $c-a$ & $90.0^{\circ}$ & $a-r$ & $147.6^{\circ}$ \\
$z-z$ & $121.1^{\circ}$ & $c-r$ & $122.4^{\circ}$ & $a-\eta$ & $151.2^{\circ}$ \\
$V-V$ & $123.0^{\circ}$ & $c-d$ & $141.8^{\circ}$ & $a-W$ & $159.9^{\circ}$ \\
$W-W$ & $124.0^{\circ}$ & $c-\gamma$ & $162.5^{\circ}$ & $a-v$ & $164.6^{\circ}$ \\
$n-n$ & $128.0^{\circ}$ & $c-n$ & $118.8^{\circ}$ & $a-z$ & $169.6^{\circ}$ \\
$r-r$ & $86.1^{\circ}$ & $c-W$ & $110.1^{\circ}$ & $a-v$ & $174.8^{\circ}$ \\
$r-V$ & $148.0^{\circ}$ & $c-v$ & $105.4^{\circ}$ & $a-\omega$ & $175.5^{\circ}$ \\
$r-W$ & $152.0^{\circ}$ & $\mathcal{c}-z$ & $100.4^{\circ}$ & & \\
$r-n$ & $154.0^{\circ}$ & $c-v$ & $95.2^{\circ}$ & & \\
$d-n$ & $148.0^{\circ}$ & $\mathcal{c}-\omega$ & $94.5^{\circ}$ & & \\
$r-d$ & $133.0^{\circ}$ & & & & \\
\hline
\end{tabular}

a For the values of $\delta$, see lable 1 . 


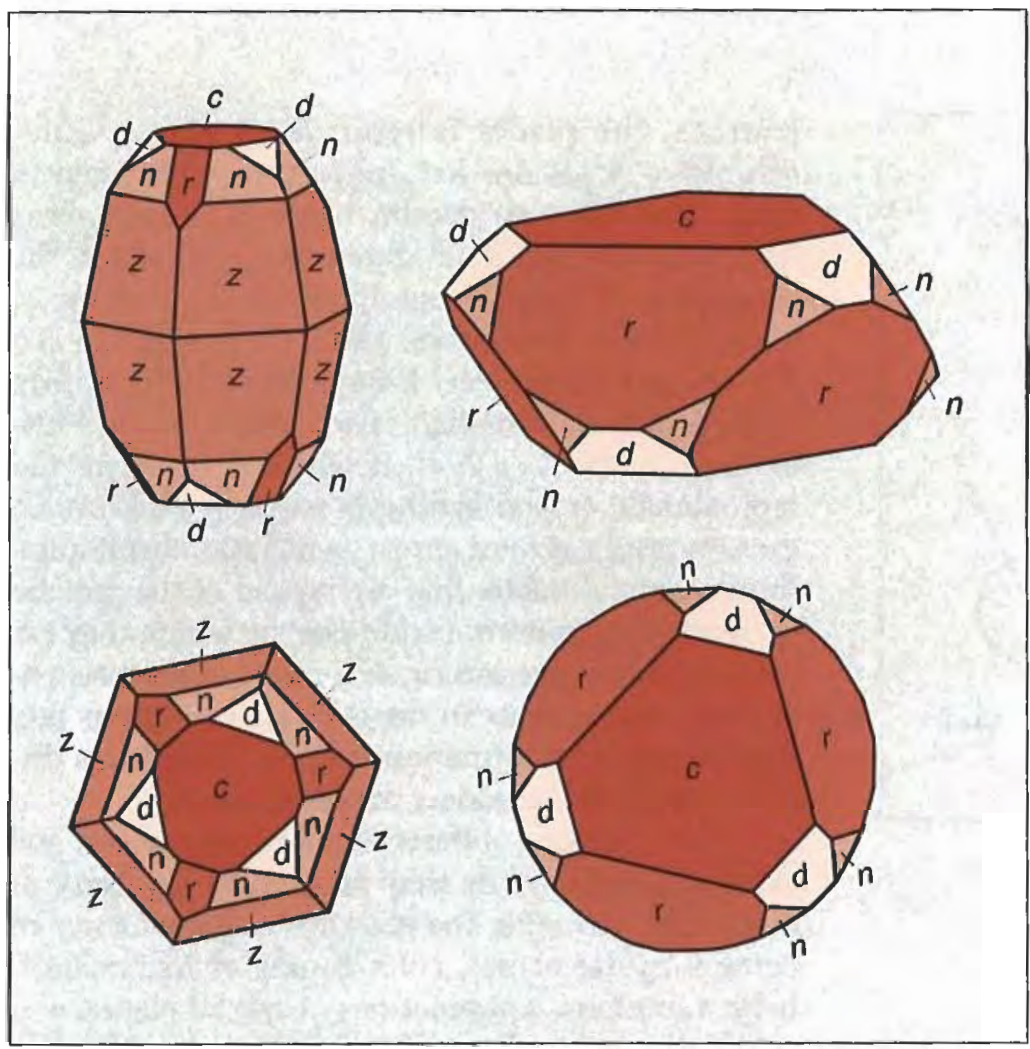

Figure 10. These diagrams illustrate the position of the negative rhombohedral $\mathrm{d}$ (0112) and other crystal faces in the mor phology of natural and synthetic corundum. The drawing on the left recreates the probable original crystal habit for the 4.51 ct natural nuby described in this article, with the optic axis of the crystal inclined slightly from the vertical; the drawing below is of the same crystal viewed parallel to the optic axis (to illustrate how different crystal planes may look at different orientations in the three-dimensional crystal). Note the location of the negative $\mathrm{d}$ face from the terminations, or ends, of the crystal and between two $n$ faces. On the Douros flux-grown synthetic ruby crystal shown on the right, the negative $\mathrm{d}$ face also connects to the positive $\mathrm{r}$ face, as well as to the $\mathrm{c}$ and $\mathrm{n}$ faces. Note how the relative prominence of the various crystal faces can dramatically affect the overall appearance of the crystal. The presence of faces other than $\mathrm{c}, \mathrm{r}, \mathrm{n}$, and $\mathrm{d}$ suggests natural origin.

corundum crystal, extending from the basal pinacoid $c(0001)$, between two dipyramidal or prism faces, and opposite a positive rhombohedral $r(10 \overline{1} 1)$ face (figure 10). This crystal face has been reported historically in natural corundum (Bauer, 1896; Dana and Dana, 1904; Goldschmidt, 1918; Bauer and Schlossmacher, 1932). However, it appears that Max Bauer (1896) is the only source where a ruby crystal with a negative rhombohedral $d(01 \overline{1} 2)$ face was actually examined and illustrated. The other references appear to be citing Bauer (1896) as their source of the information. In the more modern literature, the negative $d$ face has been described as representing a subordinate crystal form that, if present in natural corundum, would be very small (Schmetzer, 1986a). However, no references can be found in the modem literature to the observation of a negative rhombohedral $d(01 \overline{1} 2)$ plane on or in a natural ruby. This has led to the suggestion that the presence of a more dominant negative $d$ plane, which is commonly found in synthetic ruby, can be used as an indication of synthetic origin (Schmetzer, 1985, 1986a and b; Kiefert and Schmetzer, 1991a-c).

As part of the gemological examination of several hundred rubies, the author used internal growthstructure analysis, incorporating the combination of both methods described previously. These analyses revealed the presence of subordinate and, in some cases, dominant negative rhombohedral $d(01 \overline{1} 2)$ planes in rubies that other tests proved were natural.

Materials and Methods. A total of eight natural rubies, between $0.15 \mathrm{ct}$ and more than $25 \mathrm{ct}$, were identified with the negative rhombohedral $d(01 \overline{1} 2\rangle$ crystal plane as part of their original habit (table 3). Two had been purchased in northern Vietnam by Dr. Eduard ). Gübelin (Lucerne, Switzerland) and Mr. Saverio Repetto (previously director of FINGEMS, Chiasso, Switzerland)-1.34 and $0.15 \mathrm{ct}$, respectively - and had been represented to them as originating from the Luc Yen mining region. Two others $(7.03$ and $25.55 \mathrm{ct})$ were reportedly from the Mogok Stone Tract in Myanmar, according to the clients who submitted them to the Gübelin Gemmological Laboratory for testing. The remaining four were also submitted to the Gübelin Gemmological Laboratory for examination, but without any indication as to their source.

A standard refractometer, desk-model spectroscope, and electronic scale equipped with the necessary attachments for hydrostatic specific gravity measurements were used to determine that the eight samples were ruby. As part of the routine examination, as well as once the negative $d$ planes were identified, extensive tests were conducted to confirm that the stones were indeed natural. To 
establish their natural origin by means of their internal features, a binocular microscope equipped with a darkfield light source was used in conjunction with fiber-optic lighting. Both of the methods described above were used to analyze the internal growth structures and twinning characteristics. Semi-quantitative chemical analysis was performed using a Spectrace TN5000 energy-dispersive X-ray fluorescence (EDXRF) spectrometer with a special measuring routine for corundum developed by Professor $\mathrm{W}$. B. Stern of the University of Basel.

Results. The refractive indexes $\left(\mathrm{n}_{\varepsilon}=1.760-1.764, \mathrm{n}_{0}\right.$ $=1.769-1.772$; birefringence of $0.008-0.009)$, visiblerange spectra ( $\mathrm{Cr}^{3+}$ absorption bands), and specific gravity (3.98-3.99) were consistent with known properties for ruby. In addition, each of the stones had a combination of inclusion features, twinning, habit, and trace-element concentrations that provided proof of their natural origin (again, see table 3).

Among the natural inclusion features observed in these rubies were transparent, colorless, and whitish mineral inclusions; unaltered and thermally altered healed fractures; zones of dense, unaltered rutile needles (figure 11); and rutile needles that were broken as a result of heat treatment. Also noted were very fine-grained whitish clouds, "cross-hatch" or "flake-like" inclusion patterns, as well as "antennaelike" intersecting stringer formations (figure 12) and long, fine, needle-like tubules along the intersection of two or more systems of twin lamellae (commonly referred to as "boehmite needles").

When the internal growth structures provided enough information to recreate the crystal habit, typically two or more dipyramidal crystal and/or prism planes, combined with the basal and rhombohedral crystal planes, were present (figure 13; see also figure 10). The combinations of these inclusion features and internal growth structures alone provided sufficient evidence of the natural origin of the rubies described.

Observation of the Negative Rhombohedral $d(01 \overline{1} 2)$

Plane. In the eight natural rubies described in this article, the negative $d$ planes ranged from subordinate through dominant, sometimes within the same stone. The negative $d$ plane in the $1.34 \mathrm{ct}$ ruby varied slightly in prominence from subordinate to intermediate during the growth of the gem (figure 14). This ruby also had dipyramidal $w$ planes, dipyramidal $z$ planes (of varying size), positive rhombohedral $r$, and basal pinacoid $c$ planes.

TABLE 3. Properties and internal characteristics of the eight natural rubies with the $d(01 \overline{1} 2)$ plane.

\begin{tabular}{|c|c|c|c|c|c|c|c|c|}
\hline \multirow{2}{*}{$\begin{array}{l}\text { Property/ } \\
\text { Characteristic }\end{array}$} & \multicolumn{8}{|c|}{ Slone number } \\
\hline & 1 & 2 & 3 & 4 & 5 & 6 & 7 & 8 \\
\hline Inclusions & $\begin{array}{l}\text { Transparent } \\
\text { colorless crystals, } \\
\text { very fine grained } \\
\text { whitish clouds, } \\
\text { short rutile needles }\end{array}$ & $\begin{array}{l}\text { Rutile needles, } \\
\text { healed fractures }\end{array}$ & $\begin{array}{l}\text { Thermally altered } \\
\text { healed fractures }\end{array}$ & $\begin{array}{l}\text { Slringer patterns } \\
\text { cloud paiterns, } \\
\text { rutile needles, } \\
\text { transparent } \\
\text { colorless crystals, } \\
\text { "boehmite" needles }\end{array}$ & $\begin{array}{l}\text { Flake-like and } \\
\text { cross-hatch } \\
\text { cloud patterns, } \\
\text { thermally altered } \\
\text { healed fractures } \\
\end{array}$ & $\begin{array}{l}\text { Transparent and } \\
\text { whitish crystals, } \\
\text { dissolved } \\
\text { rulile needles, } \\
\text { thermally altered } \\
\text { healed fraclures }\end{array}$ & $\begin{array}{l}\text { Dissolved } \\
\text { rutile needles, } \\
\text { "boehmite" needles, } \\
\text { thermally altered } \\
\text { healed fractures }\end{array}$ & $\begin{array}{l}\text { Clusters of small } \\
\text { transparent } \\
\text { colorless crystals } \\
\text { rutile needles, } \\
\text { healed fractures }\end{array}$ \\
\hline $\begin{array}{l}\text { Evidence of } \\
\text { heat Ireatment }\end{array}$ & No & No & Yes & No & Yes & Yes & Yes & No \\
\hline $\begin{array}{l}\text { Twinning } \\
\text { parallel tor }\end{array}$ & None & 1 system & None & 2 systems & 1 system & 1 system & 2 systems & None \\
\hline $\begin{array}{l}\text { Growth } \\
\text { siructures }\end{array}$ & $\underset{r \text { and } d}{z}$ & $\begin{array}{l}c-W-Z \\
r \text { and } d\end{array}$ & $\begin{array}{l}c-z-\omega \text { or } \nu \\
r \text { and } d\end{array}$ & $\begin{array}{l}c-n-z \\
\text { rand } d\end{array}$ & $\begin{array}{l}c-n-z \\
r \text { and } d\end{array}$ & $c-d$ & $\begin{array}{l}c-n-a \\
r \text { and } d\end{array}$ & $\begin{array}{c}c-n-\omega \text { or } v \\
\text { and } d\end{array}$ \\
\hline$d$ plane & Intermediate & Subordinate & Subordinate & Subordinate & $\begin{array}{l}\text { Subordinate to } \\
\text { dominant }\end{array}$ & Dominant & Dominant & Subordinate \\
\hline \multicolumn{9}{|l|}{ Chemistry } \\
\hline $\mathrm{Al}_{2} \mathrm{O}_{3}$ & 99.7 & 99.5 & 98.5 & 99.2 & 99.3 & 99.5 & 99.0 & 98.9 \\
\hline $\mathrm{TiO}_{2}$ & 0.014 & 0.016 & 0.031 & 0.050 & 0.022 & 0.035 & 0.044 & 0.024 \\
\hline $\mathrm{V}_{2} \mathrm{O}_{5}$ & 0.032 & 0.051 & 0.027 & 0.016 & 0.016 & 0.016 & 0.034 & 0.108 \\
\hline $\mathrm{Cr}_{2} \mathrm{O}_{3}$ & 0.210 & 0.256 & 0.899 & 0.691 & 0.612 & 0.413 & 0.733 & 0.528 \\
\hline $\mathrm{Fe}_{2} \mathrm{O}_{3}$ & 0.038 & 0.093 & 0.018 & 0.023 & 0.012 & 0.003 & 0.006 & 0.009 \\
\hline $\mathrm{Ga}_{2} \mathrm{O}_{3}$ & 0.008 & 0.014 & 0.001 & 0.005 & 0.004 & 0.003 & 0.006 & 0.018 \\
\hline
\end{tabular}




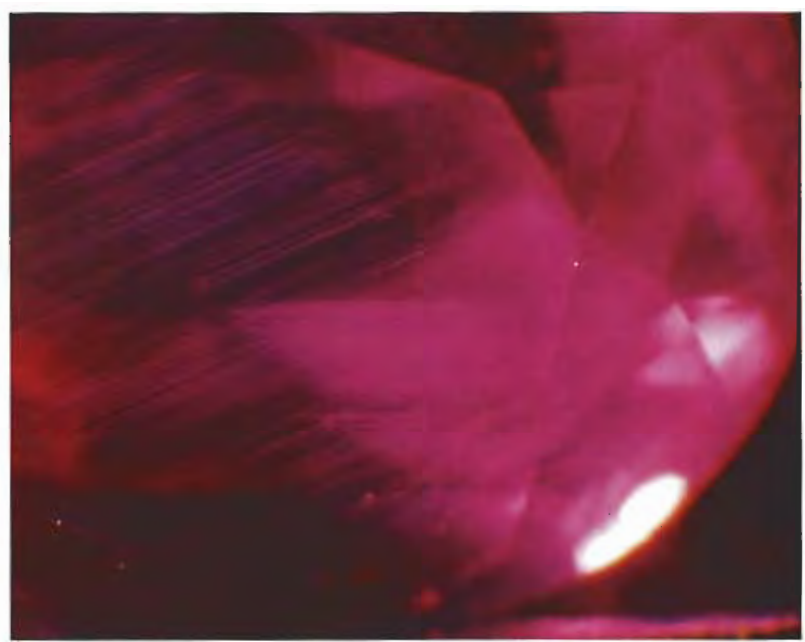

Figure 11. Unaltered nutile needles, concentrated more densely in bands parallel to subordinate negative $\mathrm{d}$ planes, provided proof of natural origin in the $1.34 \mathrm{ct}$ ruby obtained in Vietnam. Oblique fiberoptic illumination, magnified $20 \times$

A subordinate negative $d$ plane was present during most, but not all, of the growth observed in the $2.53 \mathrm{ct}$ ruby. The dipyramidal planes $\omega$ or $v$ dominated the morphology of this genstone, with subordinate $c, z$, and positive $r$ planes also present. The $4.5 \mathrm{l}$ ct ruby had $c$, positive $r$, and two different dipyramidal $-n$ and $z-$-planes, with subordinate negative $d$ planes having formed only during a brief period of crystal growth (refer again to figure 10).

Figure 12. "Antennae-like" stringer formations, a typical feature of Vietnamese rubies, helped confirm that the $4.51 \mathrm{ct}$ stone was natural. Oblique fiber-optic illumination, magnified $22 x$.

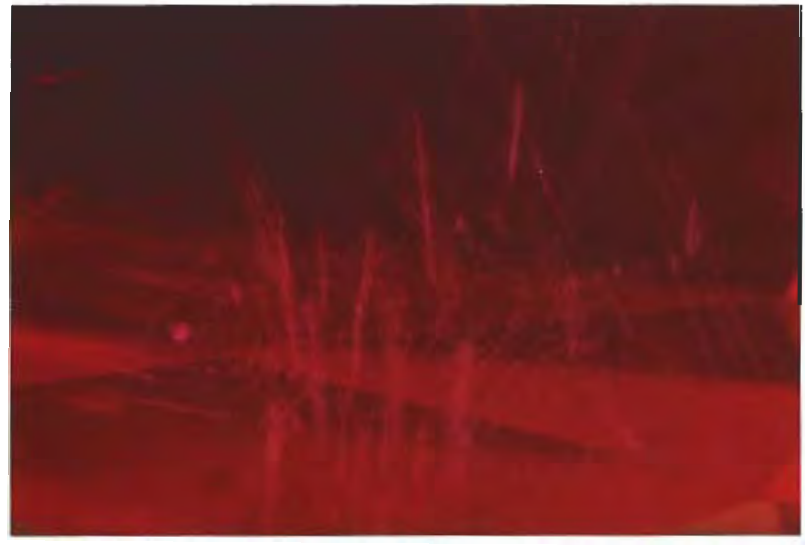

The 25.55 ct ruby displayed dominant $c$ planes and small negative $d$ planes, which were present during the earlier stages of crystal growth (figure 15), as well as subordinate $n$ planes and more dominant dipyramidal planes $\omega$ or $v$.

Negative $d$ planes and positive $r$ planes of approximately equal, intermediate size were recorded in the 0.15 ct ruby (figure 16), along with subordinate $z$ planes.

In the most striking examples, three rubies had dominant negative $d$ planes. The 7.03 ct stone showed only dominant $c$ planes along with the dominant negative $d$ planes (figure 17). In addition to its dominant negative $d$ planes (figure 18), the $10.07 \mathrm{ct}$ ruby had dominant positive $r$ planes and two systems of twin lamellae, along with dominant $c$ and $a$ planes, with more subordinate $n$ planes. Yet another sample $(6.10 \mathrm{ct})$, revealed negative $d$ planes that ranged from subordinate to dominant (figures 19 and $20)_{j}$ it also displayed $c$, positive $r$, and two series of dipyramidal $-n$ and $z$--planes (refer to figure 13).

Figure 13. Viewing the $6.10 \mathrm{ct}$ ruby perpendicular to the optic axis, revealed a well-developed growth zoning, typical of natural rubies, that consisted of the basal pinacoid c (horizontal growth planes), the hexagonal dipyramid $\mathrm{n}$ (the diagonal growth planes creating an angle of $118.8^{\circ}$ with the basal planes), and the dipyramid $z$ (the nearly vertical growth planes, with an angle of $100.4^{\circ}$ from the basal growth planes). Immersion, magnified $10 \times$.

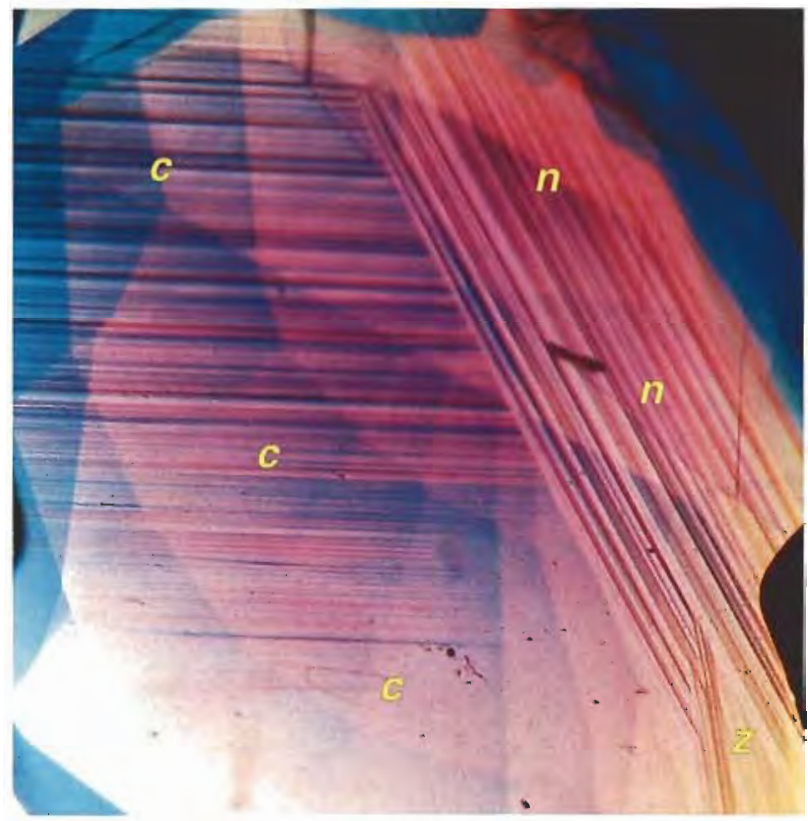




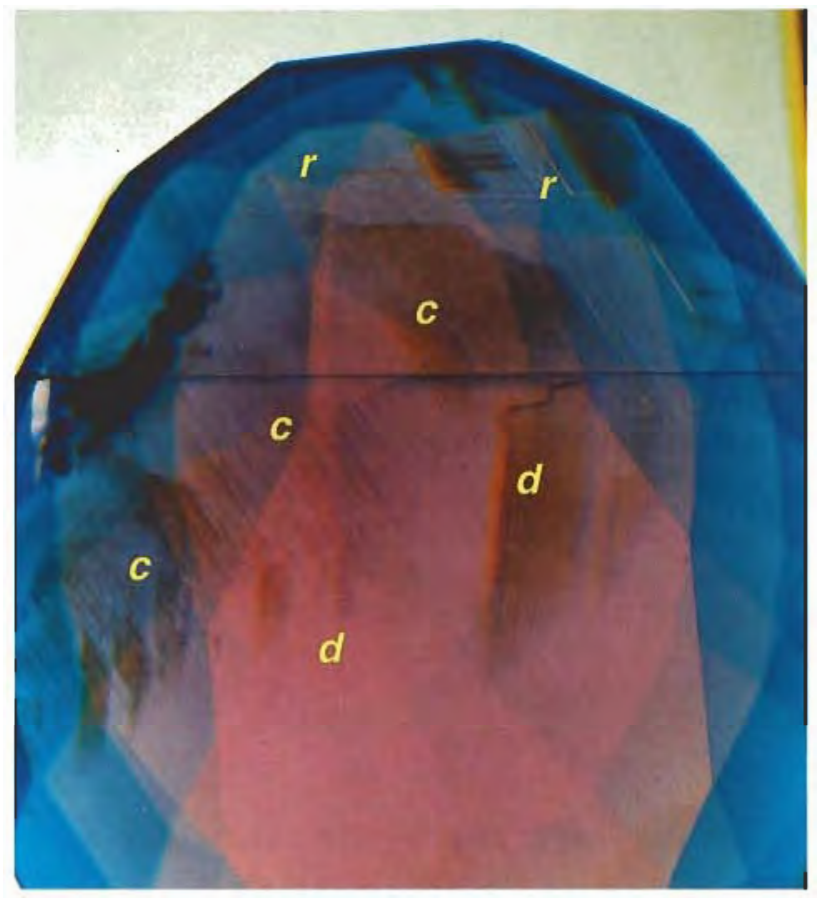

Figure 14. The negative d planes in this $1.34 \mathrm{ct}$ Vietnamese ruby varied in size slightly during the stages of growth that are visible in the faceted store, but for the most part they were subordinate. The brownish bands following the growth structures are concentrations of short rutile needles. Also notice the sharp horizontal line, which is a twin plane parallel to a positive $\mathrm{r}$ plane. Immersion, magnified $15 \times$.

\section{DISCUSSION}

Since this author first identified the negative rhombohedral $d(01 \overline{12})$ plane in a natural ruby (Smith, 1992), he has identified this crystal plane in other samples. Statistically, however, this structural feature remains very rare, having been observed in less than $1 \%$ of the several hundred corundum samples (primarily ruby and blue sapphire) measured to date by the author. The term corundum is used in this context, because the author did identify the negative $d$ plane in a natural blue sapphire loaned by Dr. H. A. Hänni, of the Swiss Gemmological Institute (SSEF), Basel; this stone also reportedly originated from northern Vietnam. Determining the conditions under which the negative $d$ plane formed in these samples is beyond the scope of this research; we can only surmise that they must have been very special.

To use the presence of the negative $d$ plane to separate natural and synthetic rubies, careful interpretation of the growth features present is para- mount. The negative $d$ plane (especially as a dominant feature) remains more common in flux-grown synthetic rubies than in natural rubies. However, the entire collection of structural features should always be used in combination with a careful analysis of the other inclusion features, as well as with the information learned from a chemical or possibly infrared spectral analysis. Whereas the basal pinacoid $c$ and the positive rhombohedral $r$ planes are typically seen in both natural and synthetic rubies, $n$ is the only dipyramid seen in synthetic rubies. Natural rubies typically contain one or any combination of $a, \omega, v, z, v, w$, or $n$.

Aside from the various inclusion features present, it was possible to identify seven of the eight

Figure 15. Basal pinacoid c planes dominated the growth structures seen in this 25.55 ct natural ruby, which was reportedly from Burma (Myanmar). The subordinate negative $\mathrm{d}$ planes were more prominent during the earlier stages of this gemstone's growth (creating an angle of $141.8^{\circ}$ ). The dark bands are concentrations of rutile needles oriented parallel to the growth planes. Immersion, magnified $15 x$.

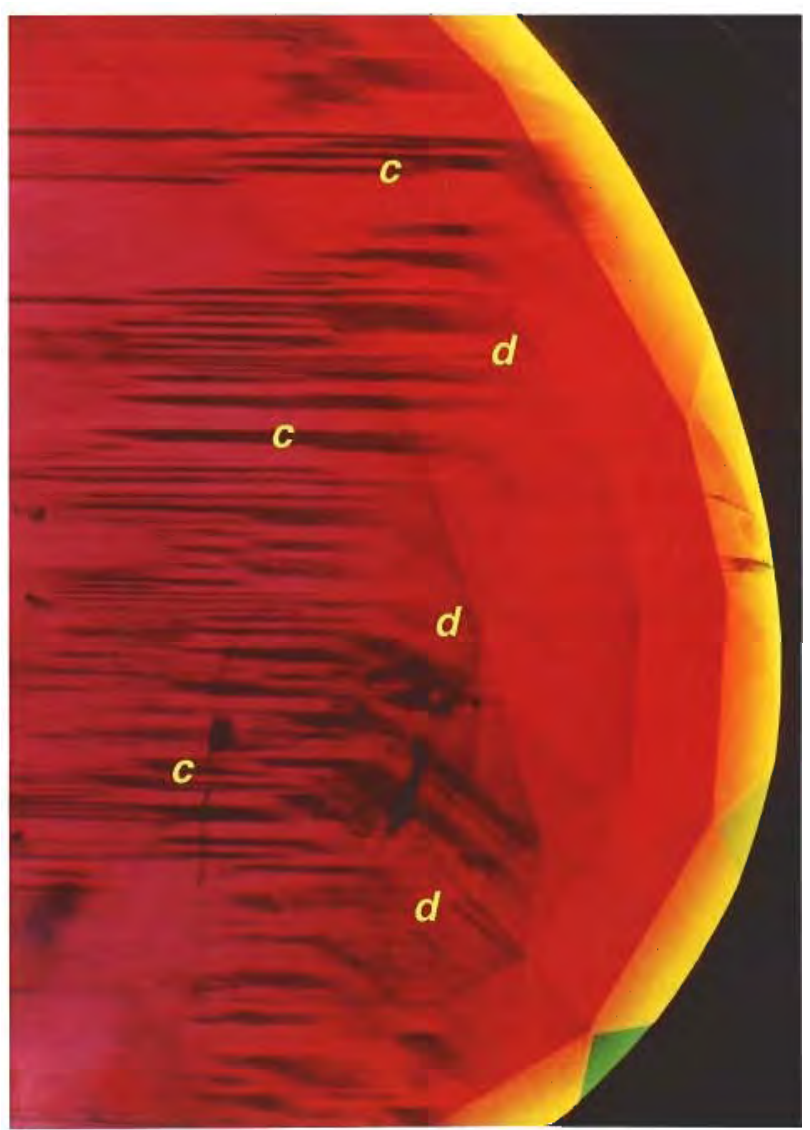




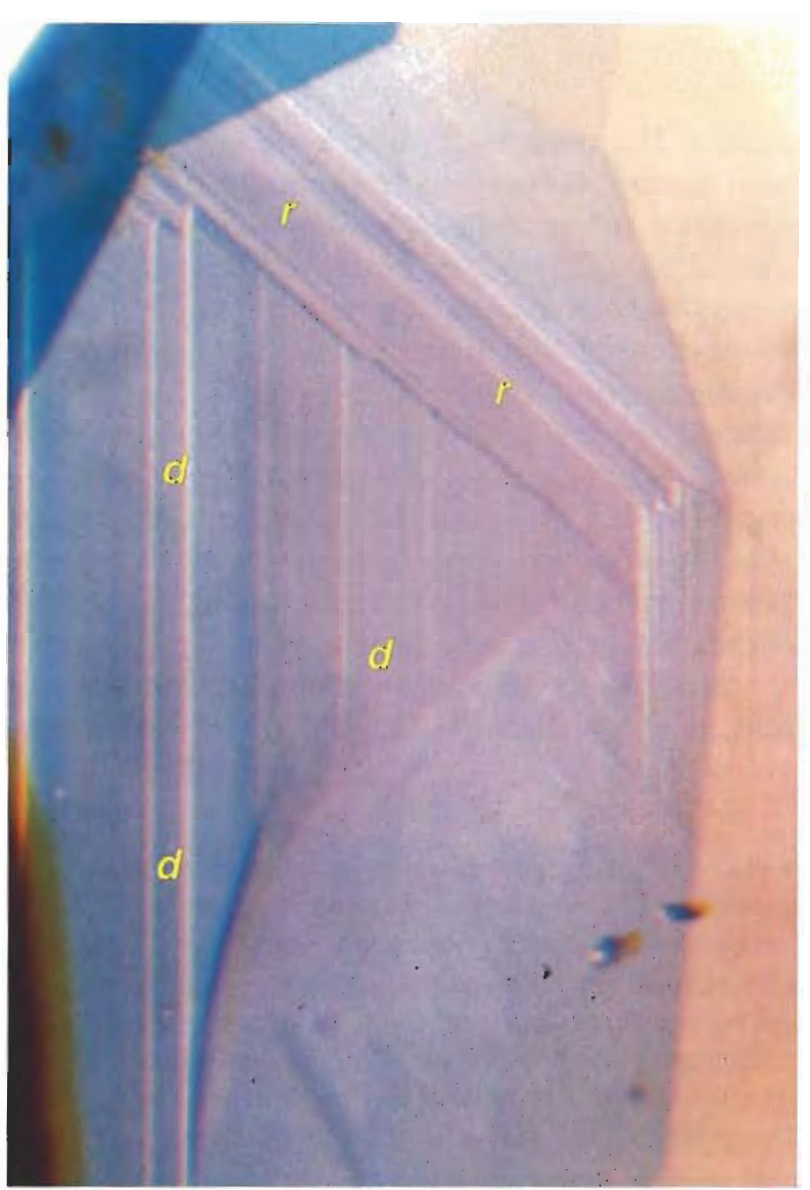

Figure 16. Intermediate negative d planes are easily seen in this $0.15 \mathrm{ct}$ Vietnamese ruby, connected to positive $\mathrm{r}$ planes. The angle created at the junction is $133.0^{\circ}$; however, the complimentary angle is also readily seen at $47.0^{\circ}(180-133=47)$.

Immersion, magnified $35 x$

rubies in the sample population /the exception was the $7.03 \mathrm{ct}$ stone) as natural by the presence of internal growth structures (again, see table 3 ) that have not been seen in flux-grown synthetics. Consequently, if a negative $d$ plane is seen in a ruby, then it is important to look also for the hexagonal dipyramid and prism crystal planes. If, in addition to the negative $d$ plane, only $c$, positive $r$, and/or $n$ are observed, care must be taken: Although this suite of features is typical for flux-grown synthetic rubies, it may also occur in natural rubies. If no characteristic inclusions are present, the use of analytical techniques such as EDXRF chemical analysis (see, e.g., Stern and Hänni, 1982) or infrared spectroscopy (see, e.g., Smith, 1995) is advised. If additional dipyramid or prism planes are present, then natural ruby is indicated. In addition, the negative rhombohedral $\gamma$ (0115) plane, located at $72.5^{\circ}$ from the optic axis, is

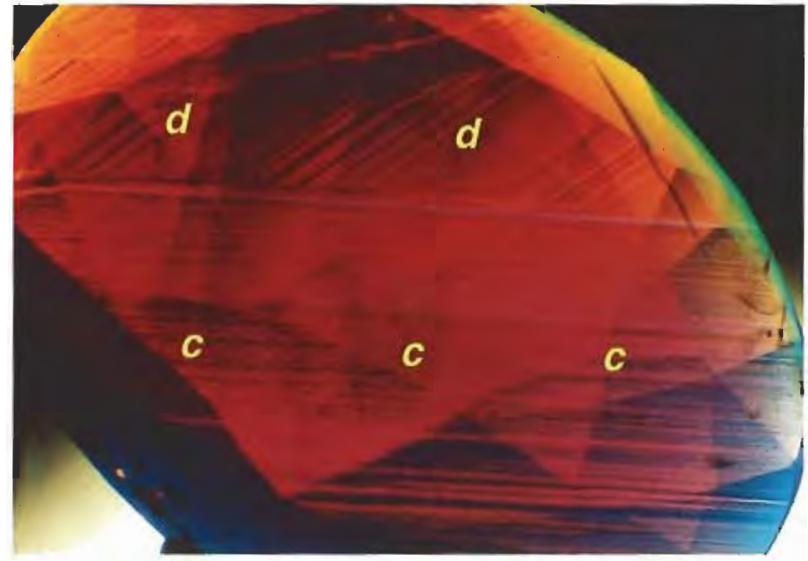

Figure 17. The most striking example comes from a $7.03 \mathrm{ct}$ nuby, reportedly from Burma (Myanmar), in which the only growth structures present consisted of dorninant $\mathrm{c}$ planes and dominant negative $\mathrm{d}$ planes, which created an angle of $141.8^{\circ}$. Immersion, magnified $18 x$.

still considered indicative of a synthetic ruby in those very rare situations where it is present (Schmetzer, 1985, 1986a and b; Kiefert and Schmetzer, $1991 \mathrm{a}-\mathrm{c}$ ).

If a negative $d$ plane is detected in a ruby of suspicious identity, then twinning characteristics can also provide important clues (Kiefert and Schmetzer,

Figure 18. Dominant negative d planes are seen in this $10.07 \mathrm{ct}$ natural ruby, creating an angle of $133.0^{\circ}$ with dominant positive $\mathrm{r}$ planes. The "checkerboard" appearance of intersecting lines is the result of twinning parallel to two positive $\mathrm{r}$ planes, forming angles of nearly $90^{\circ}$. Immersion, magnified $9 x$.

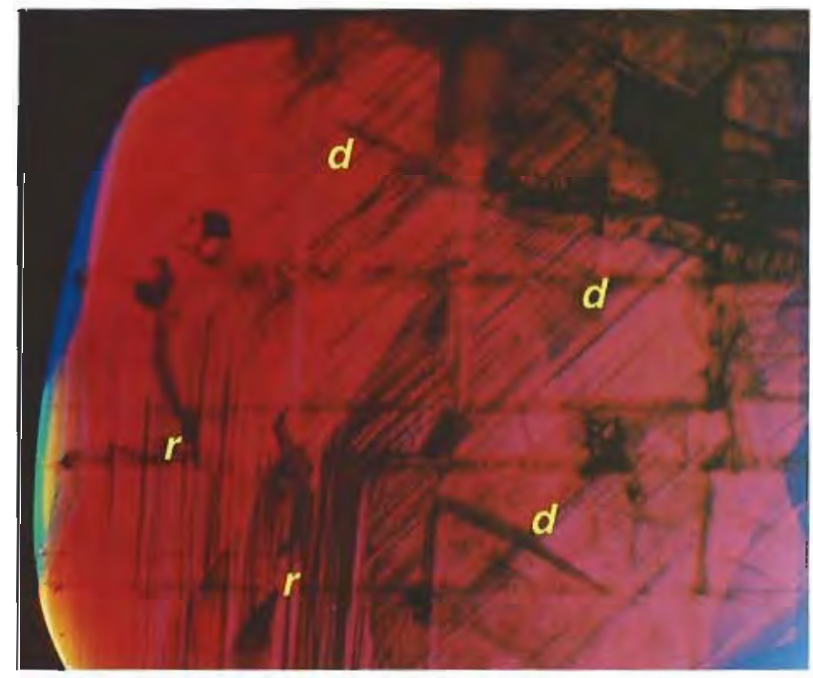




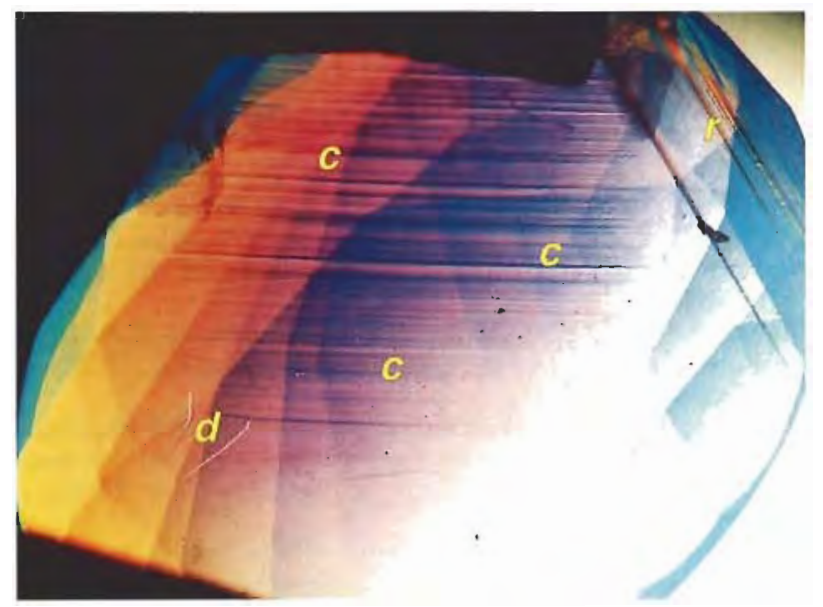

Figure 19. The negative d planes in this $6.10 \mathrm{ct}$ natural ruby ranged from subordinate to dominant. This view shows a subordinate form of negative d plane with dominant c planes. Immersion, magnified $10 \times$.

1986, 1988; Kiefert, 1987; Schmetzer, 1987, 1988). Twin planes parallel to the positive $r$ planes (commonly referred to as "laminated twinning") are common in natural rubies, but they may also be present in flux-grown synthetic rubies produced by Kashan (and, less commonly, in those from Chatham or produced by the Verneuil method). In synthetic rubies, however, only rarely will the twin planes intersect one another. In contrast, twinning in natural rubies frequently has a "checkerboard" or "lattice work" appearance (again, see figure 18; Schmetzer, 1987). Other forms of twinning observed in natural and synthetic corundum can also aid in this separation (e.g., Kiefert, 1987; Schmetzer, 1988; Schmetzer et al., 1994; Hänni et al., 1994).

With regard to how the presence of the negative $d$ plane may relate to source determinations, two of the rubies (1.34 and $0.15 \mathrm{ct}$ ) were purchased in Vietnam, and three others $(2.53,4.51$, and $6.10 \mathrm{ct})$ revealed internal features typical of Vietnamese rubies. The suppliers of two of the remaining rubies $(7.03$ and $25.55 \mathrm{ct})$ indicated that they came from Myanmar. The author was unable to determine the probable source location of the 10.07 ct ruby. It is interesting that the negative $d$ plane noted by Bauer (1896) also was reportedly in a natural ruby from Burma (now Myanmar). Therefore, it can be stated that to date the negative $d$ plane has been observed in rubiés from only two sources: Vietnam (Luc Yen) and Myanmar (Mogok Stone Tract). Whereas the author has examined five to 10 times as many Mogok as Vietnamese rubies, he has observed this plane more frequently in the Vietnamese stones.

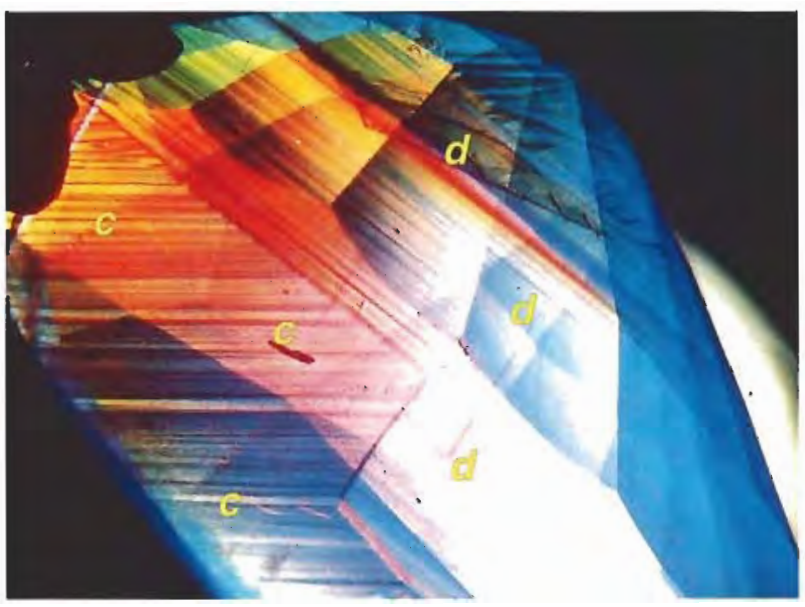

Figure 20. The $6.10 \mathrm{ct}$ ruby also displayed dominant negative $\mathrm{d}$ planes as the stone was rotated to view additional growth-structure characteristics.

Immersion, magnified $8 \times$.

\section{CONCLUSION}

The analysis of internal growth structures (internal indicators of crystal habit formation) in fashioned gemstones has been increasing in importance since it was first introduced to gemologists in 1985. The methods and principles involved can be learned and used by any gemologist with a minimum of specialized equipment. With experience, the study of growth structures-through the identification of individual and pairs of crystal planes-can help distinguish between fashioned natural and synthetic gems as well as help classify gemstones from various deposits. While this article focuses on the identification of growth planes, observations of color zoning and twinning characteristics can also provide key information relating to a natural/synthetic distinction or provenance determination (see, e.g., Schmetzer, 1987; Smith and Surdez, 1994; Peretti et al., 1995; Smith et al., 1995; Hänni et al., 1994).

According to earlier reports, the negative rhombohedral $d(0112)$ plane was extremely rare in natural rubies and occurred only as a subordinate feature. However, this article has detailed for the first time in the professional literature the occurrence of negative $d$ planes as intermediate to dominant crystal planes in natural rubies. It is potentially relevant to locality determination that to date the negative $d$ plane has been observed only in rubies from Vietnam and Myanmar. These findings reinforce the importance of not relying on any single growth feature as conclusive proof of the natural or synthetic origin of a ruby or sapphire. Instead, identification and analysis of growth structures requires keen observation and interpretation of all the observed crystallographic features. 


\section{REFERENCES}

Bauer M. (1896) Ueber das Vorkommen der Rubine in Birma. Neues Jahrbuch für Mineralogie, Geologie und Palaeontologie, Vol. 2, pp. 197-238.

Bauer M., Schlossmacher K. (1932) Edelsteinkunde, 3rd ed. Leipzig, Germany, Bernhard Tauchnitz.

Crowningshield R., Hurlbut C., Fryer C.W. (1986) A simple procedure to separate natural from synthetic amethyst on the basis of twinning. Gems \&) Gemology, Vol. 22, No. 3, pp. 130-139.

Dana J.D., Dana E.S. (1904) The System of Mineralogy, 6th ed. John Wiley and Sons, New York, London.

Goldschmidt V. (1918) Atlas der Krystallformen. Vol. 5. Carl Winters Universitätsbuchhandlung, Heidelberg, Germany.

Hänni H.A., Schmetzer K. (1991) New rubies from the Morogoro area, Tanzania. Gems \&) Gemology, Vol. 27, No. 3, pp. $156-167$.

Hänni H.A., Schmetzer K., Bernhardt H-J. (1994) Synthetic rubies by Douros: A new challenge for gemologists. Gems \&) Gemology, Vol. 30, No. 2, pp. 72-86.

Hofer S.C. (1985) Pink diamonds from Australia. Gems ed) Gemology, Vol. 21, No. 3, pp. 147-155.

Kane R.E. (1980) The elusive nature of graining in gem-quality diamonds. Gems e) Gemology, Vol. 16, No. 9, pp. 294-314.

Kane R.E. (1987) Three notable fancy-color diamonds: Purplishred, purple-pink, and reddish-purple. Gems ev Gemology, Vol. 23, No. 2, pp. 90-95.

Kiefert L., Schmetzer K. (1986) Morphologie und Zwillingsbildung bei synthetischen blauen Saphiren von Chatham. Zeitschrift der Deutschen Gemmologischen Gesellschaft, Vol. 35 , No. 3/4, pp. 127-138.

Kiefert L. (1987) Mineralogische Untersuchungen zur Charakterisierung und Unterscheidung Natürlicher und Synthetischer Saphire. Diplomarbeit Universität Heidelberg, Germany, 203 pp.

Kiefert L., Schmetzer K. (1987) Blue and yellow sapphire from Kaduna Province, Nigeria. Journal of Gemmology, Vol. 20, No. 7-8, pp. 427-442.

Kiefert L., Schmetzer K. (1988) Morphology and twinning in Chatham synthetic blue sapphire. Journal of Gemmology, Vol. 21, No. 1, pp. 16-22.

Kiefert L., Schmetzer K. (1991) The microscopic determination of structural properties for the characterization of optical uniaxial natural and synthetic gemstones, part 1: General considerations and description of the methods. Journal of Gemmology, Vol. 22, No. 6, pp. 344-354.

Kiefert L., Schmetzer K. (1991b) The microscopic determination of structural properties for the characterization of optical uniaxial natural and synthetic gemstones, part 2: Examples for the applicability of structural features for the distinction of natural emerald from flux-grown and hydrothermally-grown synthetic emerald. Journal of Gemmology, Vol. 22, No. 7, pp. $427-438$.

Kiefert L., Schmetzer K. (1991c) The microscopic determination of structural properties for the characterization of optical uniaxial natural and synthetic gemstones, part 3: Examples for the applicability of structural features for the distinction of natural and synthetic sapphire, ruby, amethyst and citrine. Journal of Gemmology, Vol. 22, No. 8, pp. 471-482.

Koivula J.l., Fritsch E. (1989) The growth of Brazil-twinned synthetic quartz and the potential for synthetic amethyst twinned on the Brazil law. Gems e) Gemology, Vol. 25, No. 3, pp. 159-164.

Lind T., Schmetzer K., Bank H. (1986) Blue and green beryls (aquamarines and emeralds) of gem quality from Nigeria. Journal of Gemmology, Vol. 20, No. 1, pp. 40-48.

Peretti A., Smith C.P. (1993) An in-depth look at Russia's hydrothermal synthetic rubies. JewelSiam, Vol, 4, No. 2, pp. 96-102.

Peretti A., Schmetzer K., Bernhardt H-J., Mouawad F. (1995) Rubies from Mong Hsu. Gems \& Gemology, Vol. 31, No. 1, pp. 2-26.

Rooney M-L.T., Welbourn C.M., Shigley J.E., Fritsch E., Reinitz I. (1993) De Beers near colorless-to-blue experimental gem-quality synthetic diamonds. Gems e) Gemology; Vol, 29, No. 1, pp. 38-45.

Schmetzer K. (1.985) Ein verbesserter Probenhalter und seine Anwendung auf Probleme der Unterscheidung natürlicher und synthetischer Rubine sowie natürlicher und synthetischer Amethyste. Zeitschrift der Deutschen Gemmologischen Gesellschaft, Vol. 34, No. 1, pp. 30-47.

Schmetzer K. (1986a) An improved sample holder and its use in the distinction of natural and synthetic ruby as well as natural and synthetic amethyst. Journal of Gemmology, Vol. 20, No. 1, pp. 20-33.

Schmetzer K. (1986b) Natürliche und synthetische RubineEigenschaften und Bestimmung. Schweizerbart, Stuttgart.

Schmetzer K. (I987) On twinning in natural and synthetic fluxgrown ruby. Journal of Gemmology, Vol. 20, No. 5, pp. 294-305.

Schmetzer K. (1988) A new type of twinning in natural sapphire. Journal of Gemmology, Vol. 21, No. 4, pp. 218-220.

Schmetzer K., Bernhardt H-J., Biehler R. (1991) Emeralds from the Ural Mountains, USSR. Gems \&) Gemology, Vol. 27, No. 2, pp. 86-99.

Schmetzer K., Smith C.P., Bosshart G., Medenbach O. (1994) Twinning in Ramaura synthetic rubies. Journal of Gemmology, Vol. 24, No. 2, pp. 87-93.

Shigley J.E., Fritsch E., Reinitz I., Moon M. (1992) An update on Sumitomo gem-quality synthetic diamonds. Gems eil) Gemology, Vol. 28, No. 2, pp. 116-122.

Shigley J.E., Fritsch E., Koivula J.I., Sobolev N.V., Malinovsky I.Y., Pal'yanov Y.N. (1993) The gemological properties of Russian gem-quality synthetic yellow diamonds. Gems 4$)$ Gemology, Vol. 29, No. 4, pp. 228-248.

Smith C.P. \{1992\} Contributions to the crystal growth analysis of natural and synthetic rubies: Identification of a dominant negative rhombohedral " $d$ " plane $(01 \mathrm{~T} 2$ ) in natural ruby. 60 th Anniversary Proceedings, Zeitschrift der Deutschen Gemmologischen Gesellschaft, Vol. 41, No. 4, pp. 182-183.

Smith C.P., Bosshart G. (1993) New flux-grown synthetic rubies from Greece. JewelSiam, Vol. 4, No. 4, pp. 106-114.

Smith C.P., Surdez N. (1994) The Mong Hsu ruby: A new type of Burmese ruby. JewelSiam, Vol. 4, No. 6, pp. 82-98.

Smith C.P. (1995) Contribution to the nature of the infrared spectrum for Mong Hsu rubies. Journal of Gemmology, Vol. 24, No. 5, pp. 321-335.

Smith C.P., Kammerling R.C., Keller A.S., Peretti A., Scarratt K.V., Khoa N.D., Repetto S. (1995) Sapphires from southem Vietnam. Gems ed Gemology, Vol. 31, No. 3, pp. 168-186.

Stern W.B., Hänni H.A. (1982) Energy dispersive X-ray spectrometry: a non-destructive tool in gemmology. Journal of Gemmology, Vol. 18, No. 4, pp. 285-296.

Sunagawa I. (1992) Morphology aspects of diamonds, natural and synthetic, stable and metastable growth. 60th Anniversary Proceedings, Zeitschrift der Deutschen Gemmologischen Gesellschaft, Vol. 41, No. 4, pp. 184-185. 